\section{Scar Ectopic Pregnancy}

Sir,

Caesarean scar ectopic pregnancy (SEP) is a rare kind of ectopic pregnancy. It is defined as low implantation of blastocyst on the scar in the uterus. The first case was reported in 1978.1 The estimated incidence of SEP is from $1 / 1800$ to $1 / 2500$ of all pregnancies ${ }^{2,3}$ and estimated $6.1 \%$ of all ectopic pregnancies are $\mathrm{SEP}^{4}$, which is more than that of cervical ectopic pregnancies. ${ }^{4}$

A 30-year female, presented in the Emergency Department of Gynaecology with a complaint of three months of amenorrhea with mild bleeding per vaginum (PV) and lower abdominal pain since one day. In obstetric history, she was gravida 6 para 5 with previous three caesarean deliveries with history of scar dehiscence in last caesarean section. On per abdominal examination, the abdomen was soft with mild suprapubic tenderness. On bimanual examination, OS was closed, partially effaced and ballooned in its upper part. Ultrasound revealed $12+$ weeks missed abortion, and placenta on the scar. The upper part of the uterine cavity was empty and adnexae were normal (Figure 1).

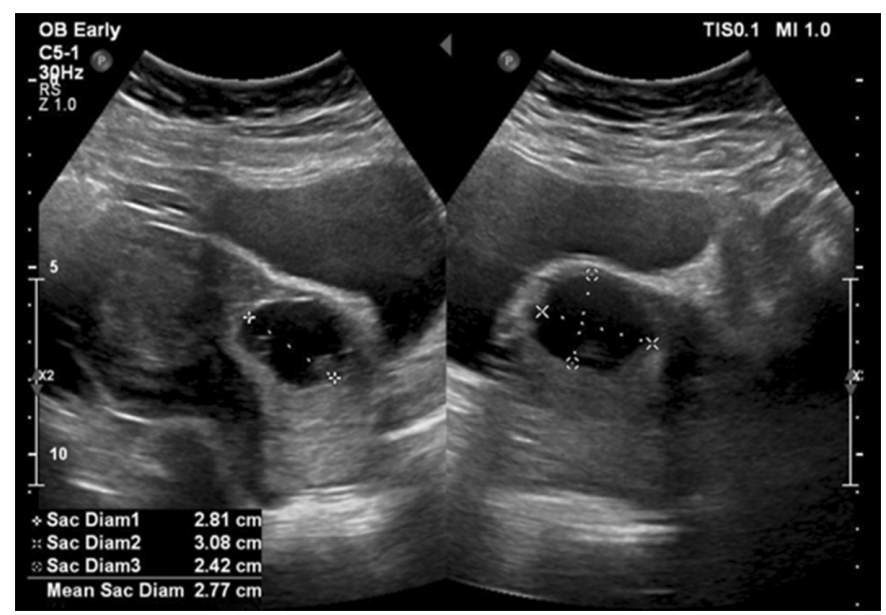

Figure 1: Ultrasound image showing low implantation of gestational sac onscar.

On Doppler examination, excessive anterior vascularity was highly suggestive of caesarean SEP. On investigations, routine hemogram, renal functions and liver functions were normal. The patient was vitally stable, so injection methotrexate 1 $\mathrm{mg} / \mathrm{kg}$ intramuscular was given. The patient was counselled about the use of methotrexate and risk of hysterectomy. On admission, $\beta$-HCG level was $1151 \mathrm{IU} / \mathrm{L}$, which was repeated after the seventh day of methotrexate administration, which decreased to $728 \mathrm{IU} / \mathrm{L}$. As patient had no PV bleeding and no pain, so she was discharged after eight days with plan of weekly $\beta$-HCG monitoring and for dilatation and evacuation after significant decrease in $\beta$-HCG result. The patient again presented after three days of discharge in Emergency Department with PV bleeding and pain. On PV examination, OS was opened, fetus was felt in the vagina, and was removed manually, followed by severe PV bleeding and shock. Patient was shifted immediately to Operation Theatre (OT). Suction evacuation was done. BAKU balloon was inserted and cerclage stitch applied. Patient was shifted to ward for observation. She continued to bleed slowly and her haemoglobin dropped, so she was again shifted to OT for laparotomy. Intraoperative finding was complete placental erosion of lower uterine segment and there was massive hemorrhage during operation. Four units of blood were transfused and subtotal hysterectomy was done to shorten the operative time and to decrease the morbidity as she was young. The patient was discharged home after the seventh postoperative day in good condition.

The incidence of SEP has been increasing due to increasing number of caesarean deliveries and decline in a trial of labour after caesarean section. History of previous scar dehiscence likely poses a risk of scar implantation, ${ }^{1}$ as in our case. Also the previous history of dilatation and curettage, myomectomy and hysteroscopy are associated with SEP. ${ }^{1}$ Due to the possibility of poor vascularity in a scar area, there is impaired healing and formation of a myometrial defect, in which the trophoblast may implant. It is a life-threatening condition, causes excessive hemorrhage and risk of uterine rupture. The diagnosis of SEP is very difficult and false-negative diagnosis can lead to major complications. Therefore, reliable diagnostic ultrasound criteria are needed. Women with SEP can be presented with various signs and symptoms, like mild or heavy vaginal bleeding and/or mild or severe abdominal pain, ${ }^{5}$ as in our case. However, up to $40 \%$ of patients remain asymptomatic before the diagnosis of SEP. ${ }^{4}$ Therefore, proper ultrasound localisation of an early gestational sac in first trimester and understanding of salient ultrasound features of SEP have an important role in reducing maternal morbidity and mortality, and providing more treatment options to preserve uterus for better future fertility. Transvaginal ultrasound has an important role in pregnancy diagnosis and localisation of SEP in the first trimester with the reported sensitivity of 86.4 percent. ${ }^{6}$ Key imaging findings include an empty uterine cavity and cervix, gestational sac in the low anterior uterine segment and thinned or absent overlying myometrium. ${ }^{7}$ High velocity and low impedance peritrophoblastic colour Doppler flow also plays a role in the diagnosis of SEP. ${ }^{8}$ Various management options are local and systemic methotrexate, laparoscopic and hysteroscopic resection and open laparotomy. Management options depend on factors like gestational age at presentation, hemodynamic stability, availability of endoscopic expertise and feasibility of follow-up by the patient. Systemic methotrexate is effective in 71 to 80 percent of cases and is most effective when $\beta$-HCG level is less than 5000 $\mathrm{mU} / \mathrm{ml}^{7}$ The combination of methotrexate with suction curettage has been shown to have greater efficacy, which justifies our management in this case. Isolated suction curettage is generally contraindicated due to high risk of incompleteevacuation, uterine rupture, and bladder injury. ${ }^{7}$ Patients who do not respond to conservative management, require laparoscopic or open excision; but uncontrollable hemorrhage due to placental invasion may necessitate hysterectomy ${ }^{8}$ In this case, history of 
previous caesarean deliveries with history of scar dehiscence in last caesarean delivery increased the risk of SEP and deep placental invasion in a scar which lead to failure of conservative measures and uncontrollable hemorrhage during laparotomy which ended up in hysterectomy.

SEP can present diagnostic and therapeutic challenges; and often combination of treatments are required to ensure complete termination of pregnancy. While, early diagnosis and termination in the first trimester is recommended to reduce the maternal morbidity and mortality.

\section{CONFLICT OF INTEREST}

Author declared that there has no conflict of interest.

\section{AUTHOR'S CONTRIBUTION:}

AK: Drafted the manuscript significantly in terms of conceiving, editing and reviewing.

\section{REFERENCES}

1. Ash A, Smith A, Maxwell D. Caesarean scar pregnancy. BJOG 2007; 114(3):253-63.

2. Seow KM, Huang LW, Lin YH, Lin MY, Tsai YL, Hwang JL. Caesarean scar pregnancy: issues in management. Ultrasound Obstet Gynecol 2004; 23(3):247-53.

3. Jurkovic D, Hillaby K, Woelfer B, Lawrence A, Salim R, Elson CJ. First trimester diagnosis and management of pregnancies implanted into the lower uterine segment Caesarean section scar. Ultrasound Obstet Gynecol 2003; 21(3):220-7.
4. Rotas MA, Haberman S, Levgur M. Caesarean scar ectopic pregnancies: Aetiology, diagnosis, and management. Obstet Gynecol 2006; 107(6):1373-81.

5. Zhang Y, Gu Y, Wang JM, Li Y. Analysis of cases with caesarean scar pregnancy. J Obstet Gynaecol Res 2013; 39(1):195-202.

6. McKenna DA, Poder L, Goldman M, Goldstein RB. Role of sonography in the recognition, assessment, and treatment of caesarean scar ectopic pregnancies. J Ultrasound Med 2008; 27(5):779-83.

7. Fenerty S, Gupta S, Anaakar J, Patel T. Caesarean scar ectopic pregnancy. Applied Radiology 2017; 46(12):20-1.

8. Vial Y, Petignat $P$, Hohlfeld P. Pregnancy in a caesarean scar. Ultrasound Obstet Gynecol 2000; 16(6):592-3.

Asma Kashif

Department of Obstetrics and Gynaecology, Jubail General Hospital, Al Jubail, Saudi Arabia

Correspondence to: Dr. Asma Kashif, Department of Obstetrics and Gynaecology, Jubail General Hospital, Al Jubail, Saudi Arabia

E-mail:dr.asmakashif@gmail.com

Received: September 02, 2019; Revised: October 16, 2019; Accepted: October 25, 2019

DOI: https://doi.org/10.29271/jcpsp.2020.08.884 